\section{RESEARCH IN GENERAL PRACTICE}

\author{
BY
}

\section{WILLIAM N. PICKLES, M.D., M.R.C.P. M.O.H., Aysgarth Rural District Council}

"I shall never have smallpox. I shall never have an ugly pockmarked face," said an eighteenth-century milkmaid, with a proper pride in her youthful beauty. "I've had cowpox, and girls who have had cowpox cannot take smallpox." That remark, made to or overheard by Jenner, is possibly a suitable beginning for this paper, as it foreshadowed an early and outstanding piece of research in general practice. Jenner at that time was apprentice to a country doctor at Sudbury, in Gloucestershire, and found that this was a well-established belief in the county.

Osler, whose historical accuracy in this matter has never been questioned, has many interesting things to say about smallpox. "For centuries it had been a popular belief among farmer-folk that cowpox protected against smallpox. The notorious Duchess of Cleveland, replying to some joker who suggested she would lose her occupation if she was disfigured with smallpox, said she was not afraid of the disease, as she had had a disease which protected her against smallpox. Jesty, a Dorsetshire farmer, had had cowpox, and in 1774 vaccinated successfully his wife and two children."

Jenner subsequently mentioned the subject to John Hunter, who in reply gave the famous advice: "Do not think, but try; be patient, be accurate." In 1780 the idea was firmly fixed in Jenner's mind, but it was not until 1796 that he made his first experiment. He extracted matter from the pustules on the hand of a dairy-maid, successfully inoculated a small boy, and six weeks later matter from a smallpox pustule produced no smallpox.

Even to-day at rare intervals a country doctor sees these pustules on the hands of a milker. I last saw a man with this condition five years ago. He told me he had never been vaccinated. "Well," I said, " that was not very wise of your parents, but you are well protected now."

Benjamin Waterhouse, of Harvard, with whom Jenner exchanged affectionate letters and presents but never met, carried on the work in the U.S.A., and with a series of successful experiments was said to have fully justified the conclusion of the Board of Health-" cowpox is a complete security against the smallpox."

The impression one gains of Jenner is of a man who realized that well-founded traditions of the countryside are worthy of notice, and of his extreme patience. "The picture is that of a likeable, clubbable fellow, who could sing a good song and turn a copy of verses, with a taste for natural history" (M. Greenwood). He has been assailed with much criticism, and not least from Creighton, who could see no good in him, even to the extent of pouring scorn on his observations as a naturalist, his observations on the behaviour of the infant cuckoo in its foster-parents' nest being characterized as a "tissue of inconsistencies and absurdities."

Greenwood, from whose Epidemics and Crowd Diseases I have acquired these facts, says: "A moving picture has been taken of a young cuckoo ejecting its foster-brother from the nest and photographs of young cuckoos conforming to Jenner's description of their structure have been exhibited at a meeting of a learned Society " ; so it would seem that in this instance Jenner was not the imaginative rascal of Creighton's showing. A man who unhurriedly followed up a country belief and patiently waited to confirm it is worthy of our regard, and many will believe that his labours were and still are the means of saving thousands of lives.

\section{An Early Epidemiologist}

When Jenner died in 1823 a boy of 12 was being brought up in the traditions of medical practice in the family home at North Tawton, Devon. He was to achieve fame in his lifetime, and, like Jenner, became a Fellow of the Royal Society; but his views were described as peculiar, and he was almost completely forgotten until a very few years ago his memory was revived, mainly by Edwin Goodall.

William Budd's Typhoid Fever is one of the treasures of the epidemiologist, and his cold reasoning is a pattern to all those who essay to study the natural history of disease. He shows particularly the advantages of country practice in the study of these problems. "How often have I seen in past days, in the single narrow chamber of the day labourer's cottage, the father in the coffin, the mother in the sick-bed in muttering delirium, and nothing to relieve the desolation of the children but the devotion of some poor neighbour who in too many cases paid the penalty of her kindness in becoming, herself, the victim of the same disorder."

William Budd was no armchair epidemiologist, as this passage shows; his contact with his patients was personal and vital and he himself had been a sufferer from this fever. He points out his own peculiar advantages: "In addition to the advantages enjoyed by country doctors generally, in the observation of such events, there were others peculiar to the position I then occupied. Having been born and brought up in the village, I was personally acquainted with every inhabitant of it ; and being, as a medical practitioner, in almost exclusive possession of the field, nearly everyone who fell ill, not only in the village itself but over a large area around it, came immediately under my care. For tracing the part of personal intercourse in the propagation of disease, better outlook could not possibly be had." Thus step by step he shows us that typhoid fever, thought in his day to be due to vague insanitary influences, was unexplainable except by the conception of contagion from one patient, directly or indirectly, to another.

But this is not all of William Budd, and, although at the time of writing the following he was a consulting physician in Bristol, one feels that it was his earlier experience in general practice which really inspired it.

"The idea that phthisis is a self-propagated zymotic disease, and that all the leading phenomena of its distribution may be explained by supposing that it is disseminated through society by specific germs contained in the tuberculous matter cast off by persons already suffering from the disease, first came into my mind, unbidden so to speak, while I was walking on the Observatory Hill at Clifton, in the second week of August, 1856. The close analogy between this disease and typhoid fever had often impressed itself upon me with great force while I was engaged in the study of the latter. . . . I now saw with a clearness, which had never occurred to me before, that with exception of the qualifications necessary for its application to a chronic disease-for the most part of slow evolution and indefinite duration-the leading conclusion to which I had been led, respecting the propagation of the fever, might be applied with the same strictness to phthisis also."

\section{A Great G.P.}

I am choosing a trio of the greatest of our general practitioners to build up my story, and the next giant is a rugged Scot who was born in Scone in 1853.

After James Mackenzie had become a partner in a practice already of high traditions in Burnley, he set out to make himself a better doctor, the idea of research never entering his head. 
"About 1883 or 1884 ," his biographer tells, "I resolved to begin a series of careful observations entirely for my own improvement, never dreaming of research, for I was under the prevalent belief that medical research could only be undertaken in a laboratory or, at least, in a hospital with all the appurtenances. ... I had recognized that when the patient had some physical sign and when disease had made considerable ravages in the body, a moderately accurate diagnosis could be made, but in the vast majority of patients there was no physical sign, or, if there was a physical sign, I was not sure of its relationship to the patient's ill-health."

He goes on to show how he began by taking notes of all his patients and then decided to narrow it down to those whose signs, and above all symptoms, were connected with the heart; and that was where general practice came in: there was continuity, and "he was waiting to see what would happen to men, women, and children who showed these symptoms," and he was able to wait.

It ill becomes me to criticize this great man whose life was as truly a success as a life could be, but I feel that he did make one mistake-that is, in leaving Burnley, and breaking this continuity-and that he himself realized this when he quietly withdrew himself from London to semiretirement at St. Andrews, where he regained something of the atmosphere of his general-practice days.

Every young doctor should read the life of this lovable man. It has been a source of inspiration to me, as it will be to hundreds of other general practitioners. It exasperated him to think that all the recognition that he received and all the honours that were heaped upon him were due to his polygraph - the very useful instrument he invented-and not to the principles underlying his work. In The Beloved Physician we learn most of what we want to know about research in general practice.

\section{A G.P. with a Hobby}

There is one among the many G.P.s who have added to the sum of human knowledge whom I cannot pass over, and his work was not strictly medical. Many doctors have done outstanding research in fields other than medicine, and I myself have known at least two distinguished antiquarians whose medical work was of a very high standard in addition.

The man I have in mind was a capable general-practitioner-surgeon whose ability in this work was recognized by the Royal College of Surgeons by the award of the rare honour of its Fellowship as a member of over 20 years' standing. Muir Evans, of Beccles, in Suffolk, who died at the age of 80 in 1947, used to say that he gave nine-tenths of his life to his profession and the remaining tenth to his hobbies. His field biology was a collateral of his work as a doctor, and his researches, beginning with the poison glands of fish, were of a very high order. In a paper on the pituitary gland of the eel, published in this Journal (April 6, 1940), he traced the seasonal changes in this gland.

One feels that a man engaged in busy practice who could produce so much in one-tenth of his working day must have done much for his patients.

\section{A Word on Record-taking}

Shortly those of us in general practice will receive a record envelope, similar to that we have become accustomed to for N.H.I. patients. I cannot stress too strongly the benefit we shall all gain if notes on these are kept conscientiously and, let me add, briefly. Thoughtful records are at the root of all good clinical work.

Let these notes also be legible. Old-fashioned people consider careless illegible handwriting a form of bad manners, and notes written in this way are valueless and a source of irritation often to those who write them. First of all a fine pen should be chosen and time taken over the procedure. The typewriter is a good get-out for the illegible writer, but I very much doubt whether it can be used in this instance; so I say to those whose education has not included calligraphy, buy a copybook and learn to write a neat legible hand.

\section{Research Through the New Health Service}

I am sad that so little has been said lately on group practice in the new Health Service. In the opinion of many there was fresh hope for the efficiency of general practice in the suggestion that doctors should work not as detached individuals but in groups-and if any contemplation of research is present, work in groups is of the highest importance.

It is not easy to indicate particular lines of research ; indeed, it is undesirable to interfere with individualism. Every man, or rather every group, should choose his or its own. The following is the sort of incident which would suggest an investigation to me.

Many years ago, in one of our villages, I saw a sad little procession approaching me. An old friend and a great village character was being brought home dead in a cart, surrounded by his sorrowing relations. He had died suddenly out in the fields. He had consulted me many times because he was the victim of an intolerable pain in one of his calves after quite a short walk. This disappeared quickly on resting (as he was bound to do), only to return on another attempt.

I was very young. I had heard of intermittent claudication (how much happier is Ryle's name for it-angina cruris), but this was the first time I had met it. This incident set me thinking. "Is it a true danger sign; ought I to have warned poor James's relatives? Are all people who suffer from this complaint candidates for being brought home dead in carts or, in other words, liable to sudden death, probably, as he was in the fields, after exertion?"

Such were the thoughts that came tumbling into my head that morning as I stood on the village green. If I understood rightly the nature of the complaint it seemed more than likely that such people would die suddenly. This, then, was my first example, and my later experience is not great, but the end has been nearly always the same. The last sufferer was a dear old lady who, dozing quietly on a Sunday afternoon, suddenly became aware that her cherished garden had been invaded by a flock of geese from the village. Jumping up in a rage to drive them out, she dropped down dead. This is the only instance $I$ have known of angina cruris in a woman.

It is an important subject, and the pooled information of a number of G.P.s would answer such questions as I asked myself that tragic morning. A group of sound general practitioners in a northern city lately, I am told, made systematic observations on the different psychological types in their patients suffering from peptic ulcer, with remarkably consistent findings.

Dental caries has always been to me a reproach as well as a fascinating problem, and I should much like to see whether painting the teeth twice-once before and once after the second dentition-with a solution of sodium fluoride really does protect against decay as our American friends tell us. Let me suggest this as a problem for a Health Centre, where I hope the examination of schoolchildren will at some future date be conducted by the family doctor, the doctor who will attend the child if he is sick, and not by the efficient but impersonal official. 
But the problems are legion, and I feel inclined to reverse the idea of Mackenzie's and to suggest that an attempt to add to medical knowledge by the investigation of particular problems would inevitably produce a better general practitioner and, incidentally, would not fail in its objective.

The point of view of the country doctor is largely epidemiological, and that in its widest sense. If he were to find a proportion of his young girl patients victims of enlargement of the thyroid gland it would be fitting of him to inquire into the local conditions and to attempt to find out if there were anything in these which might contribute to the knowledge of its causation. He might then suggest a more generous fish diet-fish is not a common article in the country diet-even if it came from the village shop in tins. He might suggest the use of iodized salt as a routine, or he might even persuade his local M.O.H. to add iodine to the water supply.

There are problems of heredity which are readily available : the hereditary nature of skin diseases such as psoriasis, of rheumatic heart disease, as well as more obvious hereditary diseases such as Huntington's chorea or Friedreich's ataxia, and conditions such as polydactyly. There are also many problems in the study of epidemic disease waiting to be solved.

Writers of textbooks on infectious disease are handicapped, and are too often bound to give approximations, say, in the length of incubation period and the duration of infectivity for want of definite information. Yet this information lies within the grasp of the country practitioner if he be interested and will give his mind to it.

In country places that short and only possible exposure which alone gives this accurate information can very often be traced in a way which is well-nigh an impossibility in a town, with the varied experience of the town dweller. Country doctors should all read William Budd's Typhoid Fever and realize in those pages how great are their opportunities and how much better and more interesting would be their work if the lead which lies close to hand were assiduously followed. Work of this sort in the field is a possibility in itself, but its value would be greatly enhanced should the practitioner form a close liaison with the director of a laboratory. This helpful co-operation is now possible, or will be possible to all in the future.

Lastly, there must be a bond between the general practitioner and the medical officer of health and the Health Services. May I plead with the M.O.H. to get to know all the general practitioners in his area and to be willing at all times to give them his help ?

Research is not a matter of gusts of inspiration but the result of patient observation undertaken with no thought of self-advancement. "In the fields of observation chance favours only the mind which is prepared." So wrote Pasteur. May those of us in general practice see that our minds are thus prepared.

A Clean Food Association has recently been formed in Caernarvonshire. It will have as its primary objects the safeguarding of the people's health and raising the hygienic standards of food production and handling. Representatives and officers of all the local sanitary authorities and of the county council, together with elected representatives of food production and handling organizations in the county, will be members of the Association. All restaurants, cafés, milk bars, etc., will be encouraged to attain and maintain a prescribed standard of cleanliness and hygiene in the preparation and handling of food, and to each establishment attaining the standard will be given an authorized certificate for display. Educational talks and film displays will be arranged for food handlers, and scientific information will be distributed to all those concerned. According to Dr. D. E. Parry-Pritchard, the County Medical Officer, Caernarvonshire is the first county in England and Wales to direct combined and co-operative efforts in this direction.

\section{MEDICAL EDUCATION IN THE UNITED STATES}

\author{
BY
}

RAYMOND WHITEHEAD, D.Sc., M.D.

(From the Department of Pathology, University of Manchester)

From the British standpoint the study of American medical education is valuable chiefly because it throws into relief the characteristic features of our own system. Although they have much in common, the British and American systems of medical education each have many distinctive features. These are expressions of the different historical circumstances of the two nations, and the possibilities of directly transferring the methods of one country to the other are accordingly limited. Mutual influence is more likely to be fruitful; ideas and principles travel better than particular applications of them, and, if adopted, it is best that they should take forms suited to the national genius. It will be helpful first of all to describe the American institutions concerned in medical education.

\section{Colleges}

The highest form of general education is given in colleges of liberal arts and sciences. These institutions have no British counterpart ; they are neither schools nor universities but have features of both. Some colleges are independent, under a president ; others form part of a university, when they are administered by a dean. There seems to be no essential difference betwen the independent and the university colleges. The primary purpose of a college is to give general education of an advanced type, but professional subjects such as engineering are sometimes taught; research work is not a normal function of a college even when it forms part of a university.

Students enter colleges as a rule at the age of 18 and follow a four-year course, receiving at its close the degree of Bachelor of Arts (A.B.) or Bachelor of Science (B.S.). The degree is obtained by accumulating a required number of credits. These are records of the satisfactory completion of a certain number of hours in a course, as shown by examinations conducted by the instructor who gives the course. Comprehensive examinations similar to those in British universities are unusual. The standard of the American college degree is probably about the same as that of a British pass degree. The difference between American college degrees and British university degrees with the same titles lies not so much in the standard as in the range of knowledge required; for American degrees this is usually wider and less directly vocational than that represented by a British B.A. or B.Sc.

\section{Universities}

The typical American university consists of a college of the kind described above and a variable number of professional schools. The term faculty is used in two senses : first, in the abstract British sense of a main division of university work, particularly postgraduate work, and, secondly, to denote the staff ("the faculty" is exactly equivalent to "the teaching staff" in British usage). The college and each school are administered by deans; their powers are wide, resembling those of an English vicechancellor, and the relation between a dean and the professors of his school is similar to that between the vicechancellor and the senate of a modern English university. The chief officer of a university is the president, and the governing body a board of trustees-men of standing in 